\title{
Papers
}

\section{Effect of peer led programme for asthma education in adolescents: cluster randomised controlled trial}

\author{
Smita Shah, Jennifer K Peat, Evalynn J Mazurski, Han Wang, Doungkamol Sindhusake, \\ Colleen Bruce, Richard L Henry, Peter G Gibson
}

\begin{abstract}
Objective To determine the effect of a peer led programme for asthma education on quality of life and related morbidity in adolescents with asthma. Design Cluster randomised controlled trial. Setting Six high schools in rural Australia. Participants 272 students with recent wheeze, recruited from a cohort of 1515 students from two school years (mean age 12.5 and 15.5 years); 251 $(92.3 \%)$ completed the study.

Intervention A structured education programme for peers comprising three steps (the "Triple A Program").

Main outcome measures Quality of life, school absenteeism, asthma attacks, and lung function. Results When adjusted for year and sex, mean total quality of life scores showed significant improvement in the intervention than control group. Clinically important improvement in quality of life ( $>0.5$ units) occurred in $25 \%$ of students with asthma in the intervention group compared with $12 \%$ in the control group $(\mathrm{P}=0.01)$. The number needed to treat was 8 (95\% confidence interval 4.5 to 35.7$)$. The effect of the intervention was greatest in students in year 10 and in females. Significant improvements occurred in the activities domain $(41 \% v 28 \%)$ and in the emotions domain $(39 \% v 19 \%)$ in males in the intervention group. School absenteeism significantly decreased in the intervention group only. Asthma attacks at school increased in the control group only.

Conclusion The triple A programme leads to a clinically relevant improvement in quality of life and related morbidity in students with asthma. Wider dissemination of this programme in schools could play an important part in reducing the burden of asthma in adolescents.
\end{abstract}

\section{Introduction}

Asthma is a major health problem among adolescents. ${ }^{1}$ Studies have identified substantial underdiagnosis and poor understanding of asthma management. ${ }^{23}$ During adolescence behavioural changes can have an adverse impact on the management of illness because adherence to treatment decreases and medical supervision becomes less consistent. ${ }^{4}$ The resulting inadequate management of asthma often leads to frequent absenteeism, hospital admissions, and also compromises a young person's education, social skills, and physical activity. ${ }^{2356}$

Traditional health education often does not meet the needs of adolescents because peers have a major and perhaps greater influence on a young person's health behaviour than parents or health staff. ${ }^{7}$ We have previously described the development of an innovative asthma education programme led by peers, known as "Triple A" (adolescent asthma action) to promote self management behaviours for asthma in adolescents. We have also shown that this programme improves knowledge and attitudes about asthma. ${ }^{9}$ We aimed to conduct a randomised controlled trial to evaluate the effect of the triple A programme on self reported quality of life and related morbidity in high school students with asthma.

\section{Participants and methods}

We recruited students from six high schools (four government, two independent) in Tamworth, rural New South Wales, Australia. Concealed random allocation was performed by PGG (who was not involved with the administration of the study), using a random number generator and the closed envelope technique. The study was approved by the research ethics committees of the Western Sydney Area Health Service and the Department of Schools Education.

A video questionnaire from the international study of asthma and allergies in childhood was administered to all students in years 7 and 10 who were present on the test day (1379 students) at each school in February 1998. ${ }^{10}$ Consenting students reporting recent wheeze (272 students) underwent baseline spirometry and completed questionnaires on asthma quality of life and asthma symptoms. The triple A programme was then implemented in the three intervention schools, and students completed the same measures in October 1998, three months after the intervention was completed.

\section{Intervention and community support}

The triple A programme entrusts young people with the responsibility of educating their peers about asthma. The intervention involved a three step approach to educating and thus empowering students

\author{
Primary Health \\ Care Education and \\ Research Unit, \\ Auburn Hospital \\ and Community \\ Health Services, \\ Auburn, NSW 2144, \\ Australia \\ Smita Shah \\ director \\ Evalynn J Mazurski \\ research and \\ evaluation officer \\ Han Wang \\ statistician \\ Colleen Bruce \\ research and \\ evaluation officer \\ Children's Hospital \\ at Westmead, \\ Westmead, NSW \\ 2145, Australia \\ Jennifer K Peat \\ associate professor \\ Department of \\ Public Health and \\ Community \\ Medicine, \\ Westmead Hospital \\ Doungkamol \\ Sindhusake \\ statistician \\ School of \\ Paediatrics, \\ University of New \\ South Wales, \\ Randwick, NSW \\ 2031, Australia \\ Richard L Henry \\ professor
}

continued over

BMJ 2001;322:1-5 
Airway Research Centre, Department of Respiratory and Sleep Medicine, John Hunter Hospital, Newcastle, NSW 2310,

Australia

Peter G Gibson senior staff specialist

Correspondence to: S Shah, Department of Public Health and Community Medicine,

Westmead Hospital, Westmead, NSW 2145, Australia SmitaShah@ wsahs.nsw.gov.au with asthma. ${ }^{811}$ In step 1 , student volunteers from year 11 in each school were trained as asthma peer leaders during a six hour workshop conducted by the study team. The students learnt how to educate their peers about asthma and its management using games, videos, worksheets, and discussions as teaching tools. In step 2, teams of three to four asthma peer leaders conducted three 45 minute health lessons for each year 10 class in their school. The leaders used the teaching tools to guide students to critically analyse the barriers to asthma management. In step 3, the year 10 students developed and presented key messages learnt in the lessons to the year 7 students. The presentations by the year 10 students included short acts, dramas, and songs, with titles such as "don't smoke," "asthma can kill," and "visit your doctor."

Before the study all schools received first aid kits for asthma and asthma workshops for their school staff. ${ }^{12}$ All students known to have asthma were issued with a record card to be completed by their doctor. In addition, a workshop on adolescent asthma was held for the local doctors, with regular reports of the study in the local print and electronic media.

\section{Measurements}

Students who reported recent wheeze completed a validated paediatric asthma quality of life questionnaire. ${ }^{13}$ The questionnaire contained 23 items organised in three domains: symptoms, activities, and emotional impact of asthma. The mean total score of the questionnaire ranged between 7 (no impairment) and 1 (most severe impairment). Students also completed a questionnaire concerning school absenteeism, asthma attacks at school, whether their asthma had been diagnosed by a doctor, and current asthma drugs. ${ }^{3}$ Students performed at least three reproducible forced expiratory manoeuvres using a Vitalograph bellows spirometer (Vitalograph, Buckingham, England) before and 10 minutes after inhalation of $200 \mu \mathrm{g}$ salbutamol through a pressurised metered dose inhaler with a valved holding chamber (Volumatic, Allen and Hanburys, Victoria, Australia). The best forced expiratory volume in one second and forced vital capacity were recorded, compared with predicted values, ${ }^{14}$ and the response to the bronchodilator calculated as the percentage change from the baseline value.

\section{Analysis}

Data were analysed with STATA (STATA, College Station, TX). Comparability of groups was examined using an unpaired $t$ test or $\chi^{2}$ test as appropriate. The effect of the intervention was described by the change within subjects from baseline to after the intervention and compared between groups using a two way analysis of variance with repeated measures. Analysis of variance was used to assess the effect of confounding by sex, year (7 or 10), and school cluster, and we calculated adjusted effect sizes. To test for a cluster effect, the intraclass (school) correlation coefficient was calculated using one way analysis of variance, and differences between groups and outcome measurements were adjusted for the clustering effect. ${ }^{15}$

The primary outcome measure was quality of life. The mean difference in overall quality of life scores was normally distributed and analysed as the total questionnaire score and as scores for each domain.

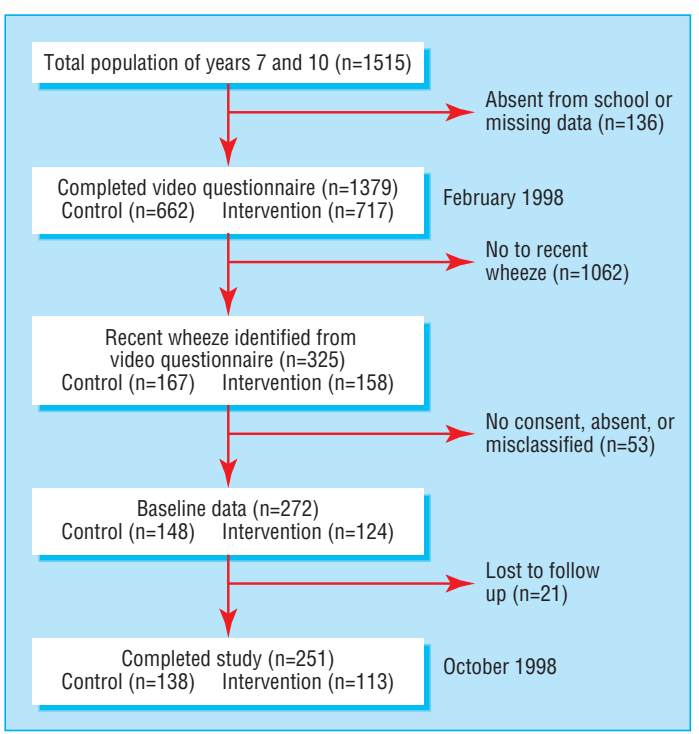

Fig 1 Flow of students through trial

Quality of life was also classified as the proportion of students who achieved a clinically important improvement in scores (a change of more than 0.5 units $^{16}$ ), and this was compared with $\chi^{2}$ statistics. We analysed the proportions of students reporting asthma attacks at school with McNemar's test. School absenteeism was compared with the Wilcoxon signed rank test. Significance was taken as $\mathrm{P}<0.05$.

\section{Results}

Overall 1379 (91\%) students completed the asthma screening questionnaire; 325 reported recent wheeze and $272(83.7 \%)$ participated in baseline testing (fig 1). Matched data at both baseline and after the intervention were available for 251 students. Missing data occurred owing to misclassification, students moving schools or being absent on the day of testing, or failure to complete the questionnaire. These students were similar to the participants in terms of quality of life and related morbidity measures.

More females were in the intervention than control group $(74(65 \%)$ and $63(46 \%)$, respectively). This occurred because cluster randomisation was used to assign the schools to study groups; four schools were coeducational and two were single sex. Asthma that had been diagnosed by a doctor was reported in $75 \%$ (189 students) of the students with recent wheeze. At baseline, students reported mild to moderate impairment of quality of life due to asthma (table 1), with females reporting greater impairment than males (5.3 $v 5.7$, respectively). All components of the programme were implemented to plan, with full participation by the target group.

\section{Quality of life}

Mean total quality of life scores after the intervention were 5.7 for the control schools (mean difference of $0.12,95 \%$ confidence interval 0.05 to 0.18 ) and 5.5 in the intervention schools $(0.21,0.12$ to 0.30$)$. Quality of life scores improved significantly after adjusting for year and sex in the intervention than control group; the intervention group improved by on average 0.12 


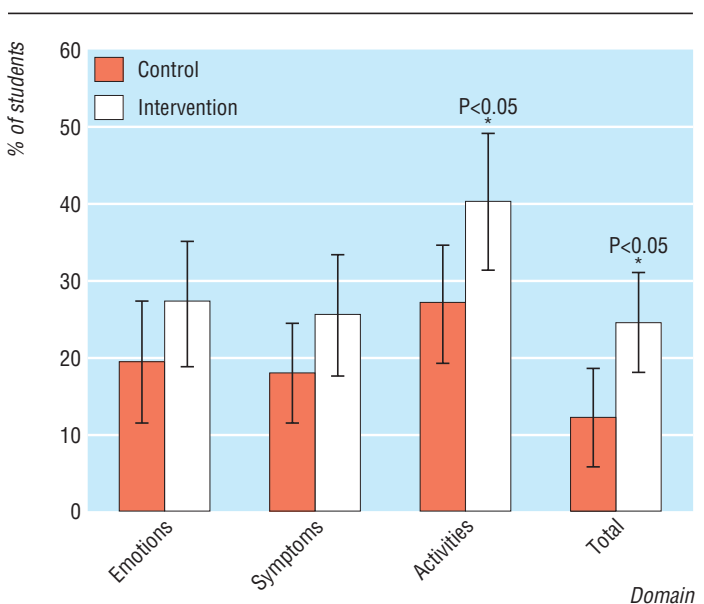

Fig 2 Percentage of students whose total quality of life score improved by more than 0.5 units in each domain



Fig 3 Median number of days absent from school for year 10 students with asthma

units more than the control group. No significant effect of clustering was found owing to the study design. The intraclass (school) correlation coefficient was less than 0.002 for the total score in all domains.

A clinically relevant improvement in quality of life was reported by $25 \%$ (28 students) of students with asthma in the intervention group compared with $12 \%{ }^{17}$ in the control group. In the intervention group significant improvements in quality of life scores occurred in the activities domain but not in the symptoms and emotions domains (fig 2). Male students showed a significant improvement in the emotions domain (table 2).

\section{Morbidity from asthma}

After the intervention there was a significant decrease in the median number of days absent from school $(8 v$ 5 days) in year 10 students in the intervention group (fig 3), with no significant difference in the control group (5.5 $v 4$ days). The proportion of students reporting asthma attacks at school in year 10 increased in the control group $(21.2 \% v 34.8 \%)$. No change was found in the intervention group (24.2\% v 25.8\%, fig 4). The intervention had no effect on school absenteeism and asthma attacks in year 7 students. At baseline both the intervention and control groups had good lung function (table 1). At follow up there was an overall improvement in lung function in both groups, with no intervention effect (table 3).

\section{Discussion}

A structured programme for asthma education led by peers can lead to an improvement in self reported quality of life in adolescents with asthma. On average eight students would need to be educated by their peers for one student with asthma to report a clinically significant improvement in quality of life. The education programme influenced different domains in males and females. For males the effect of the intervention was most apparent in the emotions domain, for females the activities domain. This is of clinical importance because the differences between sexes indicate areas that need to be targeted. ${ }^{12}$

The measurement tools included the video questionnaire from the international study of asthma and allergies in childhood, which has been widely used

Table 1 Characteristics of students with wheeze in control and intervention groups. Values are numbers (percentages) unless stated otherwise

\begin{tabular}{|c|c|c|c|c|}
\hline & \multicolumn{2}{|c|}{ Control group $(n=138)$} & \multicolumn{2}{|c|}{ Intervention group $(n=113)$} \\
\hline & Year 7 & Year 10 & Year 7 & Year 10 \\
\hline No of students & 71 & 67 & 47 & 66 \\
\hline Female & $31(44)$ & $32(48)$ & $29(62)$ & $45(68)$ \\
\hline Mean age (years) & 12.5 & 15.5 & 12.5 & 15.5 \\
\hline Asthma diagnosed by doctor & $51(72)$ & $46(69)$ & $39(83)$ & $53(80)$ \\
\hline $\begin{array}{l}\text { Mean percentage predicted change in } \\
\text { forced expiratory volume in one second }\end{array}$ & 99.2 & 105.7 & 101.8 & 105.3 \\
\hline $\begin{array}{l}\text { Mean percentage change in forced } \\
\text { expiratory volume in one second:forced } \\
\text { vital capacity }\end{array}$ & 89 & 89.4 & 89.3 & 89.8 \\
\hline Mean (SD) total quality of life score & $5.7(1.3)$ & $5.5(1.3)$ & $5.1(1.5)$ & $5.4(1.2)$ \\
\hline Taking inhaled corticosteroids & $25(35)$ & $20(30)$ & $18(38)$ & $28(42)$ \\
\hline Taking bronchodilator alone & $18(25)$ & $20(30)$ & $15(32)$ & $20(30)$ \\
\hline Taking asthma drugs & $43(61)$ & $40(60)$ & $33(70)$ & $48(73)$ \\
\hline
\end{tabular}

Table 2 Percentage of students with clinically significant improvement in quality of life ( $>0.5$ units) in control and intervention groups. Values are numbers (percentages) unless stated otherwise

\begin{tabular}{|c|c|c|c|c|c|}
\hline Domain & $\begin{array}{c}\text { Control group } \\
(n=138)\end{array}$ & $\begin{array}{l}\text { Intervention } \\
\text { group }(n=113)\end{array}$ & $\begin{array}{c}\% \text { difference } \\
(95 \% \mathrm{Cl})\end{array}$ & $P$ value & $\begin{array}{l}\text { Number } \\
\text { needed } \\
\text { to treat }\end{array}$ \\
\hline Mean total quality of life: & $17 / 138(12)$ & $28 / 113(25)$ & 12.5 (2.8 to 22.1$)$ & 0.01 & 8 \\
\hline Year 7 & $14 / 71(20)$ & $16 / 47(34)$ & $14.3(-2.1$ to 30.7$)$ & 0.08 & 7 \\
\hline Year 10 & $3 / 67(5)$ & $12 / 66(18)$ & 13.7 (3.2 to 24.2 ) & 0.01 & 7 \\
\hline Male & $11 / 75(15)$ & 9/39 (23) & $8.4(-7.1$ to 23.9$)$ & 0.26 & 12 \\
\hline Female & $6 / 63(10)$ & $19 / 74(26)$ & 16.2 (3.8 to 28.5$)$ & 0.02 & 6 \\
\hline Activities: & $38 / 138(28)$ & $46 / 113(41)$ & 13.2 (1.4 to 24.9 ) & 0.028 & 8 \\
\hline Year 7 & $21 / 71(30)$ & $26 / 47(55)$ & 25.7 (8.0 to 43.5 ) & 0.005 & 4 \\
\hline Year 10 & $17 / 67(25)$ & $20 / 66(30)$ & $4.9(-10.3$ to 20.1$)$ & 0.53 & 20 \\
\hline Male & $23 / 75(31)$ & $17 / 39(44)$ & 12.9 (-5.8 to 31.7$)$ & 0.17 & 8 \\
\hline Female & $15 / 63(24)$ & $29 / 74(39)$ & 15.4 (0.1 to 30.7$)$ & 0.06 & 7 \\
\hline Symptoms: & $25 / 138(18)$ & $29 / 113(26)$ & $7.6(-2.8$ to 17.9$)$ & 0.15 & 13 \\
\hline Year 7 & $14 / 71(20)$ & $14 / 47(30)$ & 10.1 (-6.0 to 26.1$)$ & 0.21 & 10 \\
\hline Year 10 & $11 / 67(16)$ & $15 / 66(23)$ & $6.3(-7.1$ to 19.8$)$ & 0.36 & 16 \\
\hline Males & $17 / 75(23)$ & $13 / 39$ (33) & 10.7 (-6.9 to 28.2$)$ & 0.22 & 9 \\
\hline Females & $8 / 63(13)$ & $16 / 74(22)$ & $8.9(-3.5$ to 21.4$)$ & 0.17 & 11 \\
\hline Emotions: & $27 / 138(20)$ & $31 / 113(27)$ & $7.8(-2.7$ to 18.4$)$ & 0.14 & 13 \\
\hline Year 7 & $16 / 71(23)$ & $14 / 47(30)$ & $7.3(-9.0$ to 23.5$)$ & 0.38 & 14 \\
\hline Year 10 & $11 / 67$ (16) & $17 / 66(26)$ & $9.3(-4.4$ to 23.1$)$ & 0.19 & 11 \\
\hline Male & $14 / 75$ (19) & $15 / 39$ (39) & 19.8 (2.2 to 37.4$)$ & 0.02 & 5 \\
\hline Female & $13 / 63(21)$ & $16 / 74(22)$ & $1.0(-12.7$ to 14.7$)$ & 0.89 & 100 \\
\hline
\end{tabular}




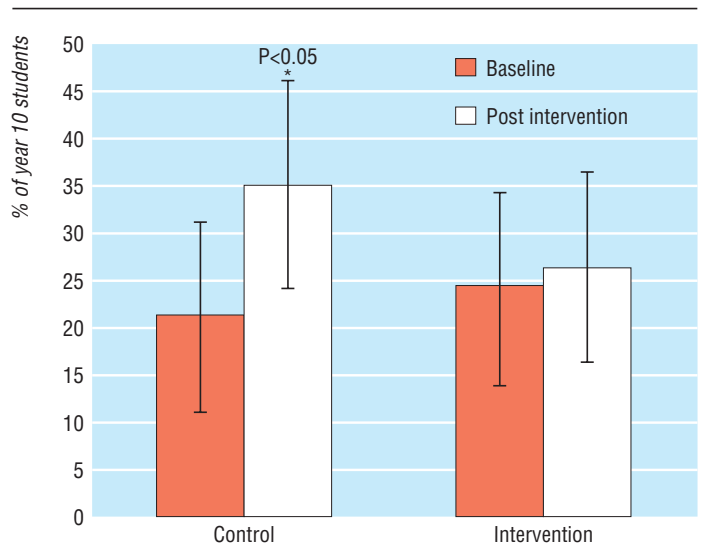

Fig 4 Proportion of year 10 students reporting an asthma attack at school

to assess the prevalence of asthma. ${ }^{10}$ The prevalence of wheeze in the past 12 months was $23 \%$ in the target student population, which was consistent with that recorded in neighbouring regions, ${ }^{13}$ suggesting that these students were representative of adolescents in rural regions.

The paediatric asthma quality of life questionnaire has been evaluated and reported to be a reliable instrument that is responsive to change and discriminates among asthmatics with varying impairments caused by asthma. ${ }^{13}$ The assessment of quality of life in adolescents with asthma was complicated by several factors. Firstly, intermittent symptoms of asthma and seasonal variations could have influenced fluctuations in their quality of life. The baseline study was undertaken in February (end of summer) whereas the other data were collected in mid-October (spring) to meet the schools' timetables. Secondly, the respondents did not always use the same activities (35 options) when completing the quality of life questionnaires at baseline and after testing. Finally, contamination was possible because there was community awareness of the study. This could have introduced a bias, known as the "Hawthorne effect," resulting in perceived improvements in the control group.

The intervention had no effect on lung function. These results are consistent with studies of asthma education that have shown improvement in quality of life after asthma education without changes in lung function. ${ }^{17} 18$

The self management of asthma is recognised as an effective strategy in reducing morbidity. ${ }^{19}$ In the past, education programmes in the self management of asthma have focused on primary school children or adults. ${ }^{19}{ }^{20}$ Initiatives for asthma education for young people, aimed at individuals with asthma, have had minimal impact on asthma morbidity, ${ }^{20}$ and education programmes conducted in hospitals have problems attracting young people. ${ }^{21}$ In our study, the students who were educated by their peers had a lower number of reported asthma attacks and school absenteeism compared with the control group. Improvements in quality of life and asthma morbidity failed to cascade from year 10 into year 7 because the year 7 students only received the performances about asthma and not the peer led teaching.

Interventions using peer education may have a higher chance of success in adolescence than other types of interventions. ${ }^{22}$ In a meta-analysis of 143 programmes in drug prevention in adolescents, the effect size was largest for peer teaching programmes than for other teaching strategies. ${ }^{23}$ Young people seem to prefer peers for advice, and change is more likely to occur if someone they can relate to or perceive as a role model relays the message. Additionally, peer educators enhance the programme's effect by directing peer pressure in a positive direction.

The triple A programme is the first peer led programme in asthma education utilising senior students as educators to show improvement in quality of life in students with asthma. This builds on our earlier work, which showed that the programme is well received by adolescents and improves knowledge about asthma and its management. ${ }^{89}$ Wider dissemination of this programme in schools could play an important part in reducing the burden of asthma in adolescents.

We thank the Tamworth schools, staff, and students as well as Kate Roese and Robin Schoeffel for their assistance in data collection.

Contributors: SS initiated the research, formulated the study protocol, helped select the quality of life tool, coordinated the study and intervention on site, and participated in data collection, interpretation, and writing and editing of the paper. JKP helped to supervise the data analyses and helped with the interpretation of the results and editing. EJM participated in the data collection at follow up and the preparation and analysis of the database. HW was responsible for the analysis and reporting of the quality of life data. DS was responsible for the analysis and reporting of the spirometry and morbidity data. $\mathrm{CB}$ assisted in interpretation of the data and editing of the paper. RLH was involved in the original study design, including liaison with doctors and media interviews, and advised on data analysis and editing. PGG was responsible for the study design and identification and selection of measurement tools, participated in planning data analysis and interpretation, wrote the first draft

Table 3 Lung function results at baseline and follow up in control and intervention groups. Values are mean (95\% confidence intervals)

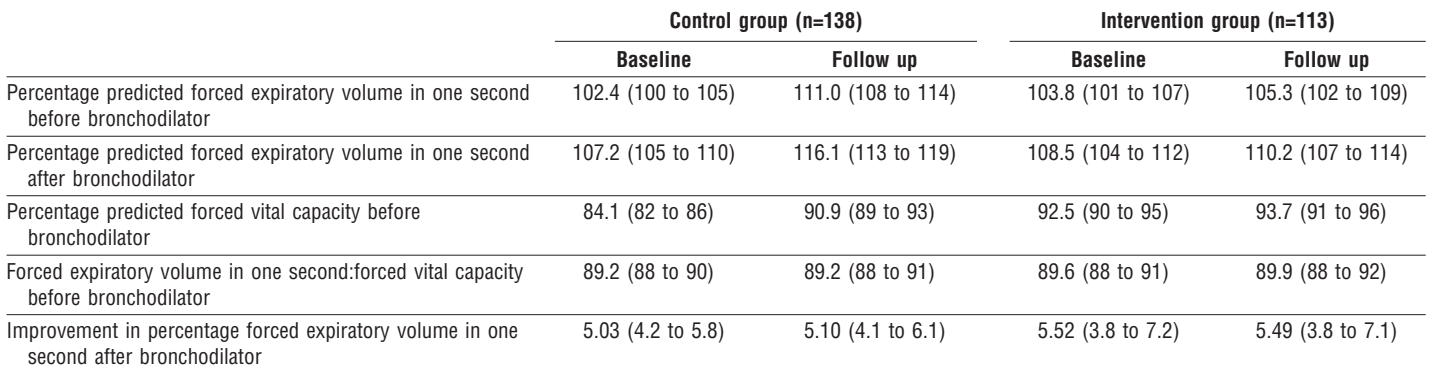




\section{What is already known on this topic}

Asthma is a major health problem among adolescents in Australia

This age group's understanding of asthma is generally poor, adherence to treatment is decreased, and medical supervision is less consistent; these are compounded by a poor understanding of asthma management

\section{What this study adds}

The triple A programme addresses asthma self management through peer led education and can play an important part in reducing the burden of asthma in adolescents

Eight students need to be educated by their peers for one student with asthma to report a significant improvement in quality of life

of the paper, and edited the paper. SS and PGG will act as guarantors for the paper.

Funding: The Commonwealth Department of Health and Aged Care and Asthma NSW funded this study.

Competing interests: None declared.

1 Forero R, Bauman A, Young L, Larkin P. Asthma prevalence and management in Australian adolescents: results from three community management in Australian adolescents:
surveys. J Adolesc Health 1992;13:707-12.

2 Siersted HC, Boldsen J, Hansen HS, Mostgaard G, Hyedebrandt N. Population based study of risk factors for underdiagnosis of asthma in adolescence: Odense schoolchild study. BMJ 1998;316:651-7.

3 Gibson PG, Henry RL, Vimpani GV, Halliday J. Asthma knowledge, attitudes, and quality of life in adolescents. Arch Dis Child 1995;73:321-6.

4 Fotheringham MJ, Sawyer MG. Adherence to recommended medical regimes in childhood and adolescence. J Pediatr Child Health 1995;3:72-8.

5 Taylor WR, Newacheck PW. Impact of childhood asthma on health. Paediatrics 1992;90:657-62.
6 Graetz B, Shute R. Assessment of peer relationships in children with asthma. J Paediatr Psychology 1995;20:205-16.

7 Nutbeam D, Haglund B, Farley P, Tillgren P, eds. Youth health promotion: from theory to practice in school and community. London: Forbes, 1991:89-107.

8 Shah S, Mamoon AH, Gibson PG. Peer-led asthma education for adolescents: development and formative evaluation. Health Prom Aust $1998 ; 8: 177-82$

9 Gibson PG, Shah S, Mamoon AH. Peer-led asthma education for adolescents: impact evaluation. J Adolesc Health 1998;22:66-72.

10 Crane J, Beasley R, Stewart B, Shaw R, Pearce N, Burgess C. The international asthma video questionnaire for measuring asthma prevalence in different populations. Int Arch Allergy Immuno 1995; 107:450-1

11 Wallerstein N, Bernstein E. Empowerment education: Frieire's ideas adapted to health education. Health Educ Q 1988;15:379-94.

12 Shah S, Gibson PG, Wachinger S. Recognition and crisis management of asthma in schools. Paediatr Child Health 1994;30:312-5.

13 Juniper EF, Guyatt GH, Feeny DH, Ferrie PJ, Griffith LE, Townsend M. Measuring quality of life in children with asthma. Qual Life Res 1996;5:35-46.

14 Hibbert ME, Lannigan A, Landau IL, Phelan PD. Lung function values from a longitudinal study of healthy children and adolescents. Paediatr Pulmonol 1989;7:101-9.

15 Rosier M. Some further ideas on analysis of cluster samples. Aust Epidemiol 1999;6:10-3

16 Juniper EF, Guyatt GH, Willan A, Griffiths LE. Determining a minimal important change in a disease-specific quality of life instrument. J Clin Epidemiol 1994:47:81-7.

17 Ringsberg KC, Wiklund I, Wilhelmsen L. Education of adult patients at an "asthma school": effects on quality of life, knowledge and need for nursing. Eur Respir J 1990;3:33-7.

18 Yoon R, McKenzie DK, Bauman A, Miles DA. Controlled trial evaluation of asthma education programme for adults. Thorax 1993;48:1110-6.

19 Gibson PG, Wilson AJ, Coughlan J, Hensley MJ, Abramson MJ, Bauman $\mathrm{A}$, et al. The effects of self-management asthma education and regular practitioner review in adults with asthma. Cochrane Database Syst Rev 1998;4:CD001005

20 Bernard-Bonnin AC, Stachenko S, Bonin D, Charette C Rousseau E. Selfmanagement teaching programs and morbidity of paediatric asthma: a meta analysis. J Allergy Clin Immunol 1995;95:34-41.

21 Yoon R, McKenzie DK, Miles DA, Bauman A. Characteristics of attenders and non-attenders at an asthma education programme. Thorax 1991;46:886-90.

22 Millistein SG, Petersen AC, Nightingale EO. Promoting the health of adolescents. New directions for the twenty-first century. New York: University Press, 1993.

23 Tobler NS. Drug prevention programs can work: research findings. J Addict Dis 1992;11:12-28.

(Accepted 1 December 2000) 